\title{
Analysis of the Technological Process of Cleaning Raw Cotton from Small Trash
}

\author{
Ozod Rajabov $^{1}$, Ziyodullo Shodiyev ${ }^{2}$, Ikrom Inoyatov ${ }^{3}$, Mastura Gapparova ${ }^{4}$ \\ ${ }^{1}$ Department of Technological Machines and Equipment, Bukhara Engineering Technological Institute, \\ Bukhara, Uzbekistan, ozodbek7504@ gmail.com \\ ${ }^{2}$ Head of the educational and methodical department of the Bukhara branch of the Tashkent Institute of Irrigation \\ and Agricultural Mechanization Engineers, Bukhara, Uzbekistan. \\ ${ }^{3}$ Department of Water resources and land reclamation, Bukhara branch of the Tashkent Institute of Irrigation and \\ Agricultural Mechanization Engineers, Bukhara, Uzbekistan. \\ ${ }^{4}$ Department of Technological Machines and Equipment, Bukhara Engineering Technological Institute, \\ Bukhara, Uzbekistan
}

\begin{abstract}
The article analyzes the treatment of raw cotton from small waste. It provides information on current scientific research in the field of cotton ginning around the world. The results of the proposed multi-faceted grid bars full-factor experiment are given. The equations that determine the cleaning effect are obtained, and the graphs of the connections are made to determine the optimal values of the parameters. It draws graphs of the cleaning efficiency of the machine depending on the number of edges of the multi-sided grid bars, the gap between the pile cylinder and the grid bars, the coefficient of elasticity of the flexible base on which the grid bars is installed. Based on the analysis of the obtained graphs, the optimal values of the recommended polygonal grid bars parameters were determined.
\end{abstract}

Key words : Cotton, Fibrous material, Trash, Feeder, Spiky Cylinder, Grid bars, Moment, Power, Elasticity, Effect.

\section{INTRODUCTION}

Cotton fiber is the main raw material used in the global textile industry. According to international statistics and the International Cotton Advisory Committee (ICAC), "the top five exporters of cotton fiber include: USA, India, Australia, Brazil and Uzbekistan, as well as importers - Bangladesh, Vietnam, China, Turkey and Indonesia." In these countries, special attention is paid to the dynamic and sustainable development of the ginning industry, the introduction of modern equipment at the enterprises of the industry, improving the efficiency and rational use of production capacities, which are the basis for competitiveness in the global cotton market. In this regard, further improving the consumer properties of cotton products on a global scale, together with improving their quality indicators, reducing their cost, ensuring the efficiency of the cotton cleaning process, improving cotton ginning machines and creating resource-saving technologies remains one of the important tasks.

On a global scale, due to the large volume of clogged cotton, especially cotton-harvested, while improving the technique of primary processing of cotton, the development of theoretical foundations for cleaning cotton from small and large trash, substantiation of motion parameters, as well as operating modes of working bodies and mechanisms, due to they are conducting advanced theoretical and comprehensive experimental studies to determine the optimal values of geometric and kinematic sizes, providing loosening and cleaning of cotton. At the same time, ensuring the efficiency of cotton cleaning and preserving the preliminary quality indicators of cotton, including the creation of mathematical models that allow the selection of optimal cleaning modes from small trash that do not negatively affect the quality of cotton and based on their decisions, determine the recommended parameters, reduce strong blows when loosening and cleaning of trash, the development of soft regime technologies, the creation of structures of resource-saving working bodies are especially important [1]. Scientific research aimed at the production of drying and cleaning technology for raw cotton is carried out in many leading research centers of the world, including the Southwest Cotton Ginning Laboratory Ginning Laboratory, Texas Tech University, Samuel Jacobson Incorporated, USDA, USDA Ginning Cotton Research, US Department of Agriculture, Agricultural Research Service (USA), Cotton research and development corporation (Australia), National Research Center for Cotton Processing Technologies, China Cotton Industries Limited, Shandong Swan Cotton Industrial Machinery Stock, Cotton Research Institute Nanjing, Swan Agricultural University (China), Central Institute for Cotton Research, Bajaj Steel Industries Ltd (India), Balkan Cotton Ginning Machinery Ltd. (Brazil), Brazilian Agricultural Research Corporation (Brazil), Tashkent Institute of Textile 
Ozod Rajabov et al., International Journal of Emerging Trends in Engineering Research, 8(9), September 2020, 6022 - 6029

and Light Industry, Namangan Engineering and Technology Institute, Pakhtasanoat Ilmiy Markazi JSC (Uzbekistan).

Studies to improve the cotton cleaning technique and technology in the world have been carried out by scientists such as W.S. Anthony, R.M. Sutton, V. Baker, P.A. Boving, J.W. Laird, V.G. Arude, S.K. Shukla, T.S. Manojkumar, D.W. Van Doom and B.M. Norman and others.

However, the studies on cotton cleaning so far, the technologies used in foreign and local ginneries and the analysis of cleaning machines and working parts and mechanisms, are aimed at changing their effectiveness, based on determining the trajectory of the working bodies and cotton components in the cotton cleaning process. The tasks of developing new designs that provide soft shock operating modes and highly efficient cleaning of the spiky cylinder and grid bars have not been resolved effectively.

\subsection{The scientific novelty of the research is as follows}

An effective technology of the cleaning process has been developed by improving the design of the spiky cylinder and the grid bars of the machine for cleaning cotton from small trash; graphical dependences of the change in the cleaning effect on the change in the number of faces of the cylinder spiky and the grid bars, as well as on the distance between the spiky and the grid bars are constructed.

\subsection{The practical results of the study are as follows}

A technology has been developed for cleaning cotton from small trash, which allows maximum preservation of the natural properties of cotton; recommended structural design of a cylinder with multifaceted spiky and a multifaceted grid bars;

\subsection{Scientific and practical significance of the research results}

The scientific significance of the research results lies in the fact that the laws governing the movement of cotton particles on the surface of multifaceted spiky, mathematical models of the interaction speed, optimized values of the rebound of cotton during the interaction of cotton with the surface of a multifaceted grid bars are obtained, and the dependences of the influence on the cleaning effect of the number of faces of cylinder spiky and grid bars are determined surface.

The practical significance of the research results lies in the fact that, based on the research, the cleaning technology using a cylinder with multifaceted spiky and a multifaceted grid bars is improved, while the natural indicators of raw cotton are preserved to the maximum by changing the directions of the trajectory of cotton during the interaction of cotton with a multifaceted grid bars with recommended cleaning parameters that increase product quality.

\section{LITERATURE REVIEW}

2.1 A review of research to improve the technology and techniques for cleaning cotton from small trash

In the production line of cotton processing in cleaning machines for small trash, the main working bodies are the spiky cylinder and the grid bars under it. Virtually all cleaners have these elements. Design decisions are mainly aimed at the number of these working bodies and technological gaps. At the present stage of development of the technique and technology for cleaning raw cotton from small trash, the most important is the improvement of the structural elements of the working bodies of cleaners, including spike cylinders, grid barss, which, with a minimum amount of interaction with cotton, ensure maximum weed impurities from them. In addition, to ensure the necessary modes of cotton cleaning technology, use should be made of drive mechanisms, especially belt drives with variable gear ratios. The solution to these problems is relevant for the ginning industry.

In the papers [2] materials on foreign and domestic practice of cotton cleaning are given in detail. The nature of the movement of cotton volatiles in the zone from the top of the clef to the moment of impact on the reflective visor was studied, and the values of the coordinates of the points, the time and acceleration times when the cotton was hit on the reflective visor were revealed. The regularity of the process of debris removal on pecking - cylinder cleaners in the areas of the grid bars is determined.

In the papers [3] analyzed the designs and principles of action of cotton cleaners from small trash, classifies them as radial and axial system cleaners. Based on the obtained experimental data, the author claims that for the cleaning of raw cotton from small trash, and most importantly from clinging trash, a long shaking and shock action is necessary, which can be carried out either with the help of a large number of cylinders in the cleaners of the radial system, or by repeated cleaning within one working body in the cleaners of the axial system. The author considers this method to be more rational and in the work it is shown that the intensity of cleaning of raw cotton from small weed impurities in a screw cleaner depends on the impact force of the picks on the raw cotton and on the driving force of the picks, which contributes to the transfer of the raw cotton through the screw and thereby repeated clean it up. One of the main factors affecting the efficiency of the cleaning process, according to the author, is not a live section, but the size of the grid bars opening located along the raw cotton in the cleaner, which is equal to $50 \times 4.5$ $\mathrm{mm}$ according to the experimental data. In the work [4] studied the main factors affecting the excretion of trash in the cells of the sieve-emitting gratings. The well-known ideas about the nature of trash release through cells are analyzed; roughening of specks into cells upon transition from a circumferential movement along the grid to a tangent above it; the release of a speck in the cell zone under the influence of 
Ozod Rajabov et al., International Journal of Emerging Trends in Engineering Research, 8(9), September 2020, 6022 - 6029

gravity is, as it were, inhibited by the resistance force; An unequal manifestation of stationary air flows for each section of the grid along its arc. The author considers the first two factors insignificant and prefers the third factor, the significance of which was highlighted earlier in the work [5]. When studying the effect of air flows in the passage through the grid bars cell, the author found that, along with the action of general flows and random flows associated with the movement of material, characterized by averaged velocity parameters, there is a high-frequency pulsating nature of their manifestation in each grid bars cell. Works [6] were aimed at studying the impact interaction of the peg of a peg cylinder with a volat at various linear speeds of rotation of the cylinder. In [7], the design of a ripping and cleaning device was proposed, which has a variable angular velocity of rotation of the spiky cylinder, the efficiency of which was shown in the work of A. Djuraev [8]. In the works of the same author [9] presents the results of theoretical and experimental studies of the spiky cylinder of a cotton cleaner having a variable angular velocity of rotation. The results of technological experiments show that a cultivator with a drive mechanism with variable parameters significantly increases the degree of loosening and cleaning effect.

Analysis of the work [10] showed that the effect on the cleaning effect of pecking - cylinder cleaners is an increase in the area of the net due to the large angle of grasp of the cylinders and high-speed regimes of pecking - barreled cylinders. It was found that an increase in the area of the grid as well as the installation of constantly exceeding the peripheral speed of rotation of the spiky cylinders in each section increases the cleaning effect by $12-15 \%$ relative to existing ones. In the work [11] it was also found that to increase the cleaning effect of machines, their sieving surfaces should have the highest coefficient of living section. Existing purifier designs are based on a mechanical method for cleaning raw cotton. But, in place, in recent years, other methods, such as the use of compressed air [12], cleaning by vibration, etc.

In terms of the vibrational method of cleaning, it should be noted [13], which allowed revealing more widely the possibilities of this method.

A review of studies on small trash cleaners and on structural elements of working bodies of cleaners shows that the main direction in the development of ginning equipment is the intensification of the technological process by activating the working bodies, leading to an increase in the cleaning effect. It should be noted that the intensification of the process of cleaning raw cotton from small trash can be carried out by improving the technology and design of the working elements of the cleaning zone, as well as substantiating the parameters and modes of their movement on the basis of deep theoretical and experimental studies. It is important to reduce the frequency of cleaning, allowing the reduction of damage to fibers and cotton seeds. To reduce the monotony of the process of cleaning cotton from small trash, it is important to choose variable modes of movement, as well as the creation of effective designs of a spiky cylinder, grid bars, etc.

\section{MATERIALS AND METHODS}

\subsection{Multivariate experimental studies of a multifaceted grid bars on the elastic supports of the cleaner for small trash}

In studies, the following are accepted as input parameters: $\mathrm{x}_{1}$ - is the number of faces of a multifaceted grid bars;

$\mathrm{x}_{2}$ - the gap between the spiky cylinder and the grid bars, t-mm.

$\mathrm{x}_{3}$ - coefficient of stiffness of elastic supports, $\mathrm{c}-\mathrm{N} / \mathrm{m}$;

The values of the input parameters are given in table 1 .

Decisions are made according to the regression analysis program. In this case, the uniformity of the variance was estimated through the assessment of the regression coefficients according to the Student criterion; with the regression models being adequate, the Fisher criteria were used [14].

Table 1: Experiment Factor Variation Levels

\begin{tabular}{|c|c|c|c|c|c|c|c|c|}
\hline \multirow[t]{2}{*}{ № } & \multirow[b]{2}{*}{ Name of factors } & \multirow{2}{*}{ 告 } & \multicolumn{5}{|c|}{ Factor values } & \multirow{2}{*}{ 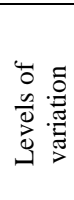 } \\
\hline & & & 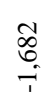 & 7 & 0 & $\mp$ & 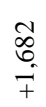 & \\
\hline 1 & $\begin{array}{l}\text { The number of } \\
\text { faces of a } \\
\text { multifaceted grid } \\
\text { bars; }\end{array}$ & $x_{I}$ & 3 & 4 & 6 & 8 & 9 & 2 \\
\hline 2 & $\begin{array}{l}\text { The gap between } \\
\text { the spiky cylinder } \\
\text { and the grid bars, } \\
\mathrm{mm} \text {. }\end{array}$ & $x_{2}$ & $\begin{array}{c}12 \\
6\end{array}$ & 14 & 16 & 18 & $\begin{array}{c}19 \\
4\end{array}$ & 2 \\
\hline 3 & $\begin{array}{l}\text { The stiffness } \\
\text { coefficient of the } \\
\text { elastic supports, } \mathrm{c}- \\
10^{3} \mathrm{~N} / \mathrm{m} \text {; }\end{array}$ & $x_{3}$ & 0,5 & 1,5 & 3 & 4,5 & 5,5 & 1,5 \\
\hline
\end{tabular}

The influence of the input parameters on the cleaning efficiency (output parameter) is studied using the experiment. To do this, we compose a planning matrix. In any conditions, experiments are carried out in 3-fold repetition. The number of experiments is determined by the following calculated expressions:

$$
N=2^{k}+2 k+n_{0}=2^{3}+2 \cdot 3+6=20
$$

In this case, the arithmetic mean values of the cleaning effect obtained as a result of the experiments are filled in table 2 [15]. Then the average value of the results is determined from the expression:

$$
\bar{Y}=\frac{\bar{Y}_{i 1}+\bar{Y}_{i 2}+\bar{Y}_{i 3}}{3}
$$

We pass from the general values of the factors to the coded values.

To obtain an expression that determines the stationary level of the regression model, it was carried out by planning the central compositional experiment. 
Ozod Rajabov et al., International Journal of Emerging Trends in Engineering Research, 8(9), September 2020, 6022 - 6029

Table 2: Planned central compositional experimental model

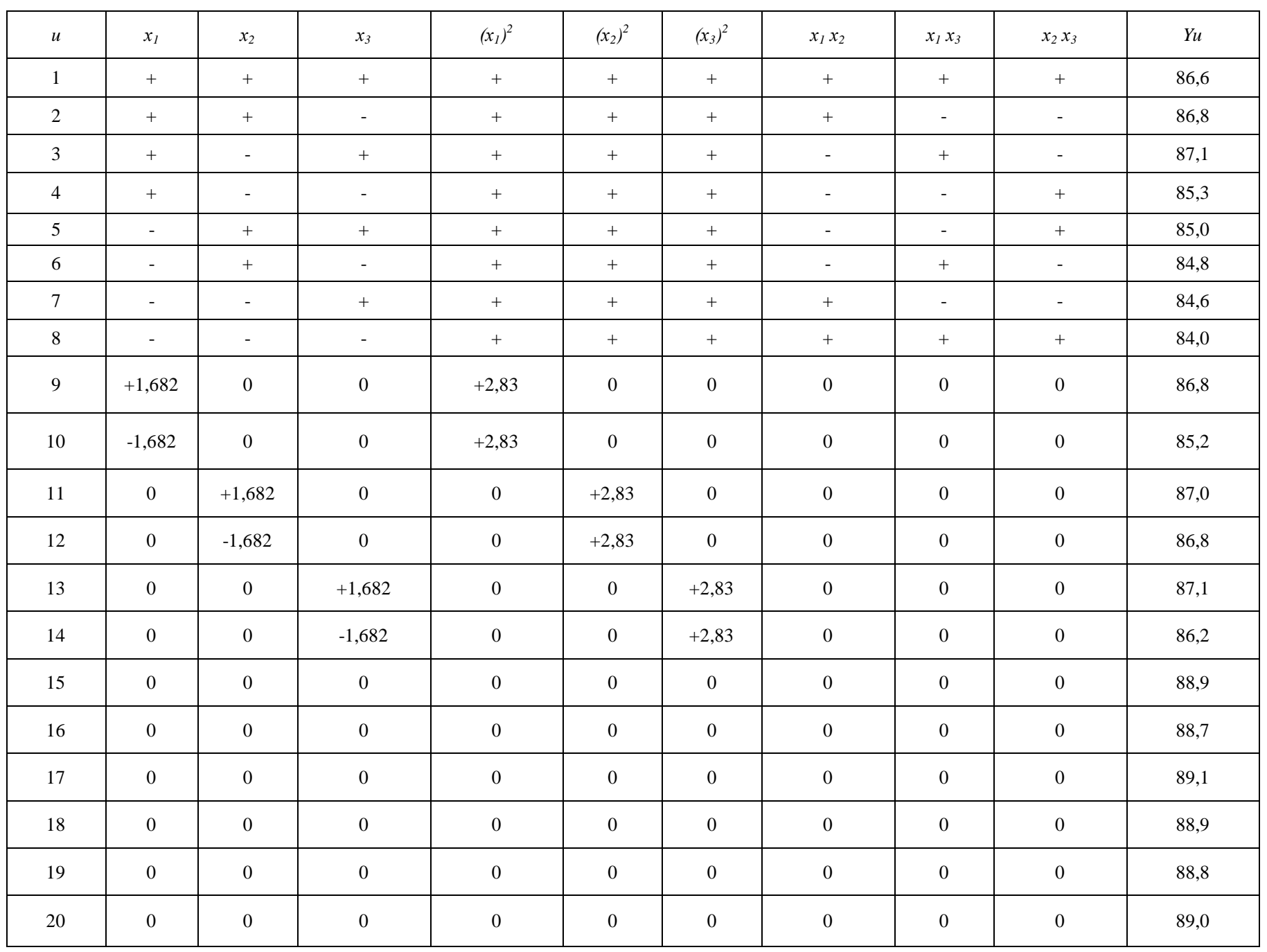

To determine the regression coefficients based on the values of table 1, using the above formulas, we preliminarily determine the following values [16]:

$$
\sum x_{1 u} Y_{u}=10,1
$$

$\sum x_{2 u} x_{3 u} Y_{u}=-2,4$

$$
\sum x_{2 u} Y_{u}=2,53
$$

$\sum x_{1 u}^{2} Y_{u}=1170,63$

$$
\sum x_{3 u} Y_{u}=3,914
$$

$\sum x_{2 u}^{2} Y_{u}=1176,05$

$$
\begin{aligned}
& \sum x_{1 u} x_{2 u} Y_{u}=-0,2 \\
& \sum x_{1 u} x_{3 u} Y_{u}=0,8
\end{aligned}
$$$$
\sum x_{3 u}^{2} Y_{u}=117463
$$

Taking into account the calculations, the regression equation has the following form:

$Y=b_{0}+b_{1} x_{1}+b_{2} x_{2}+b_{3} x_{3}+b_{12} x_{1} x_{2}+b_{13} x_{1} x_{3}+b_{23} x_{2} x_{3}$

$+b_{11} x_{1}^{2}+b_{22} x_{2}^{2}+b_{33} x_{3}^{2}$

where: $\quad \bar{Y}_{1}$ - the cleaning efficiency of the machine; $b_{0}$ - free play;

$b_{1}, b_{2}, b_{3}-$ coefficients of nonlinear moves;

$b_{12}, b_{13}, b_{23} \ldots-$ coefficients of linear strokes;

$x_{1}, x_{2}, x_{3}-$ values of coded factors.

Determine the free play of the model

$b_{0}=g_{1} \sum_{u=1}^{N} \bar{Y}_{u}-g_{2} \sum_{i=1}^{M} \sum_{u=1}^{N} x_{i u}^{2} \bar{Y}_{u}=0,1663 \cdot 1736,7-$

$-0,0568 \cdot(1170,63+1176,05+1174,63)=88,8$

$b_{1}=g_{3} \sum_{u=1}^{N} x_{1 u} \bar{Y}_{u}=0,0732 \cdot 10,1=0,739$

$b_{2}=g_{3} \sum_{u=1}^{N} x_{2 u} \bar{Y}_{u}=0,0732 \cdot 2,53=0,185$

$b_{3}=g_{3} \sum_{u=1}^{N} x_{3 u} \bar{Y}_{u}=0,0732 \cdot 3,91=0,286$

$b_{12}=g_{4} \sum_{u=1}^{N} x_{1 u} x_{2 u} \bar{Y}_{u}=0,125 \cdot(-0,2)=-0,025$

$b_{13}=g_{4} \sum_{u=1}^{N} x_{1 u} x_{3 u} \bar{Y}_{u}=0,125 \cdot 0,8=0,1$ 
Ozod Rajabov et al., International Journal of Emerging Trends in Engineering Research, 8(9), September 2020, 6022 - 6029

$b_{23}=g_{4} \sum_{u=1}^{N} x_{2 u} x_{3 u} \bar{Y}_{u}=0,125 \cdot(-2,4)=-0,3$

$b_{11}=g_{5} \sum_{u=1}^{N} x_{1 u}^{2} \bar{Y}_{u}+g_{6} \sum_{i=1}^{M} \sum_{u=1}^{N} x_{1 u}^{2} \bar{Y}_{u}-g_{2} \sum_{u=1}^{N} \bar{Y}_{u}=0,0625 \cdot 1170,83+$

$+0,0069 \cdot(1170,83+1176,05+1174,64)-0,0568 \cdot 1736,7=1,46$

$b_{22}=g_{5} \sum_{u=1}^{N} x_{2 u}^{2} \bar{Y}_{u}+g_{6} \sum_{i=1}^{M} \sum_{u=1}^{N} x_{2 u}^{2} \bar{Y}_{u}-g_{2} \sum_{u=1}^{N} \bar{Y}_{u}=0,0625 \cdot 1176,05+$

$+0,0069 \cdot(1170,83+1176,05+1174,64)-0,0568 \cdot 1736,7=-0,84$

$b_{33}=g_{5} \sum_{u=1}^{N} x_{3 u}^{2} \bar{Y}_{u}+g_{6} \sum_{i=1}^{M} \sum_{u=1}^{N} x_{3 u}^{2} \bar{Y}_{u}-g_{2} \sum_{u=1}^{N} \bar{Y}_{u}=0,0625 \cdot 174,64+$

$+0,0069 \cdot(1170,83+1176,05+1174,64)-0,0568 \cdot 1736,7=-0,93$

Based on the foregoing, the regression equation has the form:

$$
\begin{aligned}
& Y=88,8+0,739 x_{1}+0,185 x_{2}+0,286 x_{3}-0,025 x_{1} x_{2}+ \\
& +0,1 x_{1} x_{3}-0,3 x_{2} x_{3}+1,46 x_{1}^{2}-0,84 x_{2}^{2}-0,93 x_{3}^{2}
\end{aligned}
$$

To verify the adequacy of the obtained models, we use the Fisher criterion formulas. For this, experimental, calculated values of the output parameter are compared.

Table 3: The results of calculations of the output factor using the regression equation

\begin{tabular}{|c|c|c|c|c|}
\hline & $\bar{Y}_{u}$ & $Y_{R}$ & $\bar{Y}_{u}-Y_{R}$ & $\left(\bar{Y}_{u}-Y_{R}\right)^{2}$ \\
\hline 1 & 86,6 & 86,56 & 0,04 & 0,0016 \\
\hline 2 & 86,8 & 86,38 & 0,42 & 0,1764 \\
\hline 3 & 87,1 & 86,84 & 0,26 & 0,0676 \\
\hline 4 & 85,3 & 85,46 & $-0,16$ & 0,0256 \\
\hline 5 & 85,0 & 84,93 & 0,07 & 0,0049 \\
\hline 6 & 84,8 & 85,16 & $-0,36$ & 0,1296 \\
\hline 7 & 84,6 & 85,11 & $-0,51$ & 0,2601 \\
\hline 8 & 84,0 & 84,14 & $-0,14$ & 0,0196 \\
\hline 9 & 86,8 & 85,91 & 0,89 & 0,7921 \\
\hline 10 & 85,2 & 85,43 & 0,23 & 0,0529 \\
\hline 11 & 87,0 & 86,73 & 0,27 & 0,0729 \\
\hline 12 & 86,8 & 86,11 & 0,69 & 0,4761 \\
\hline 13 & 87,1 & 86,65 & 0,45 & 0,2025 \\
\hline 14 & 86,2 & 85,69 & 0,51 & 0,2601 \\
\hline 15 & 88,9 & 88,80 & 0,1 & 0,01 \\
\hline 16 & 88,7 & 88,80 & $-0,1$ & 0,01 \\
\hline 17 & 89,1 & 88,80 & 0,3 & 0,09 \\
\hline 18 & 88,9 & 88,80 & 0,1 & 0,01 \\
\hline 19 & 88,8 & 88,80 & 0 & 0 \\
\hline 20 & 89,0 & 88,80 & 0,2 & 0,04 \\
\hline Total & & & & 2,702 \\
\hline
\end{tabular}

We calculate the variance of the output parameter:

$$
S^{2}\{Y\}=\frac{\sum_{u=1}^{n_{0}}\left(\bar{Y}_{u}-Y_{R u}\right)^{2}}{n_{0}-1}=\frac{2,7}{5}=0,54
$$

Using the above expressions, we determine the variance of the regression coefficients:

$$
\begin{aligned}
& \left|S\left\{b_{0}\right\}\right|=\sqrt{S^{2}\left\{b_{0}\right\}} ; \\
& S^{2}\left\{b_{0}\right\}=g_{1} \cdot S^{2}\{Y\}=0,1663 \cdot 0,54=0,089 ; \\
& S\left\{b_{0}\right\}=0,298 \quad\left|S\left\{b_{i}\right\}\right|=\sqrt{S^{2}\left\{b_{i}\right\}} ; \\
& S^{2}\left\{b_{i}\right\}=g_{3} \cdot S^{2}\{Y\}=0,0732 \cdot 0,54=0,039 ; \\
& S\left\{b_{i}\right\}=0,197 ; \quad\left|S\left\{b_{i j}\right\}\right|=\sqrt{S^{2}\left\{b_{i j}\right.} ; \\
& S^{2}\left\{b_{i j}\right\}=g_{4} \cdot S^{2}\{Y\}=0,125 \cdot 0,54=0,0675 ; \\
& S\left\{b_{i j}\right\}=0,259 ; \quad\left|S\left\{b_{i i}\right\}\right|=\sqrt{S^{2}\left\{b_{i i}\right\}} ; \\
& S^{2}\left\{b_{i i}\right\}=g_{7} \cdot S^{2}\{Y\}=0,0695 \cdot 0,54=0,0038 ; \\
& S\left\{b_{i i}\right\}=0,062 ;
\end{aligned}
$$

By calculating the student criterion, the values of the regression coefficients are checked. We determine the coefficients of the regression equation by student's criterion.

$t_{R}\left\{b_{0}\right\}=\frac{\left|b_{0}\right|}{S\left\{b_{0}\right\}}=\frac{88,8}{0,298}=297,98$;

$t_{R}\left\{b_{1}\right\}=\frac{\left|b_{1}\right|}{S\left\{b_{i}\right\}}=\frac{0,739}{0,197}=3,75$;

$t_{R}\left\{b_{2}\right\}=\frac{\left|b_{2}\right|}{S\left\{b_{i}\right\}}=\frac{0,185}{0,197}=0,939$;

$t_{R}\left\{b_{3}\right\}=\frac{\left|b_{3}\right|}{S\left\{b_{i}\right\}}=\frac{0,286}{0,197}=1,451$;

$t_{R}\left\{b_{12}\right\}=\frac{\left|b_{12}\right|}{S\left\{b_{i j}\right\}}=\frac{0,025}{0,259}=0,096$;

$t_{R}\left\{b_{13}\right\}=\frac{\left|b_{13}\right|}{S\left\{b_{i j}\right\}}=\frac{0,1}{0,259}=0,38$;

$t_{R}\left\{b_{23}\right\}=\frac{\left|b_{23}\right|}{S\left\{b_{i j}\right\}}=\frac{0,3}{0,259}=1,158$;

$t_{R}\left\{b_{11}\right\}=\frac{\left|b_{11}\right|}{S\left\{b_{i i}\right\}}=\frac{1,46}{0,062}=23,54$;

$t_{R}\left\{b_{22}\right\}=\frac{\left|b_{22}\right|}{S\left\{b_{i i}\right\}}=\frac{0,84}{0,062}=13,54$;

$t_{R}\left\{b_{33}\right\}=\frac{\left|b_{33}\right|}{S\left\{b_{i i}\right\}}=\frac{0,93}{0,062}=15$;

The calculated values of the coefficients according to the student criterion are compared with the selected values according to the table [17] 
Ozod Rajabov et al., International Journal of Emerging Trends in Engineering Research, 8(9), September 2020, 6022 - 6029

$\left.t_{R} \succ t_{T} ; t_{T} \mid P_{D}=0,95 ; \quad f\left\{S_{u}^{2}=6-1=5\right\}\right]=2,57 ;$

If the specified condition is fulfilled, then the calculated values of the coefficients of the regression equation are considered significant, otherwise, these regression coefficients are considered not significant and displayed.

Thus, as a result of calculating $b_{0}, b_{1}, b_{12}, b_{11}, b_{22}$ and $b_{33}$, the coefficients are considered significant, and calculations continue with these coefficients. In this case, the regression equation has the form:

$$
Y=88,8+0,739 x_{1}+1,46 x_{1}^{2}-0,84 x_{2}^{2}-0,93 x_{3}^{2}
$$

To verify the adequacy of the results we use the Fisher test. For this, we compare the calculated and experimental values of the output factors [18]:

$$
\begin{gathered}
F_{R}=\frac{S_{m}^{2}\{Y\}}{S^{2}\{Y\}}=\frac{S_{n}^{2}\{Y\}}{S^{2}\{Y\}} ; \\
S_{m}^{2}(Y)=\frac{\left.\sum_{u=1}^{N}\left(\bar{Y}_{u}-Y_{R u}\right)^{2}-\sum_{u=1}^{n_{0}} \bar{Y}_{u}-Y_{R u}\right)^{2}}{N-n_{0}-\left(n_{0}-1\right)}=\frac{2,7-0,15}{20-6-(6-1)}=0,283 ; \\
F_{R}=\frac{S_{m}^{2}\{Y\}}{S^{2}\{Y\}}=\frac{0,283}{0,54}=0,52 ;
\end{gathered}
$$

Fisher criterion is found on a special table [19]:

$$
F_{T}\left[\begin{array}{l}
P_{D}=0,95 ; f\left\{S_{\text {над }}\{Y\}\right\}=20-6-(6-1)= \\
=9 ; f\left\{S_{u}^{2}\right\}=6-1=5
\end{array}\right]=3,48
$$

Therefore, $\mathrm{F}_{\mathrm{R}}<\mathrm{F}_{\mathrm{T}}$, therefore, the model is adequate, i.e. expresses, accordingly, a change in the index of the cleansing effect.

The coefficients in the regression equation express the output factors and are important. Equation (7) is inconvenient for practical calculations, therefore, the transition from coded values $\left(\mathrm{x}_{1}, \mathrm{x}_{2}, \mathrm{x}_{3}\right)$ to the actual values of factors $(\mathrm{n}, \delta, \mathrm{c})$ is carried out according to the following expressions.

$$
x_{1}=\frac{n-n_{0}}{\Delta n} ; \quad x_{2}=\frac{\delta-\delta_{0}}{\Delta \delta} ; \quad x_{3}=\frac{c-c_{0}}{\Delta c} ;
$$

Where, $n_{0}, \delta_{0}, c_{0}$ - real values of the basic equations, $\Delta n, \Delta \delta$, $\Delta c$-intermediate values. Substituting the values $n_{0}, c_{0}, \delta_{0}$ and $\Delta n, \Delta \delta, \Delta c$ into formula (12), we obtain:

$x_{1}=\frac{n-6}{2} ; x_{2}=\frac{\delta-16}{2} ; x_{3}=\frac{c-3}{10} ;$

From the expression (13) we obtain the equation of the factor in the following form:

$M_{z}=-98,94+10,76 n-0,158 n \delta-0,0705 n c+$

$+12,37 \delta+1,515 c-0,352 n^{2}-0,357 \delta^{2}-0.0104 c^{2}$

For the purpose of clarity of research, a numerical solution of the equation was carried out using a computer using the EXCEL program and graphs were obtained (Fig. 1,2,3).

\section{RESULTS AND DISCUSSION}

For the purpose of clarity of research, a numerical solution of the equation was carried out using a computer using the EXCEL program and graphs were obtained (Fig. 1,2,3).

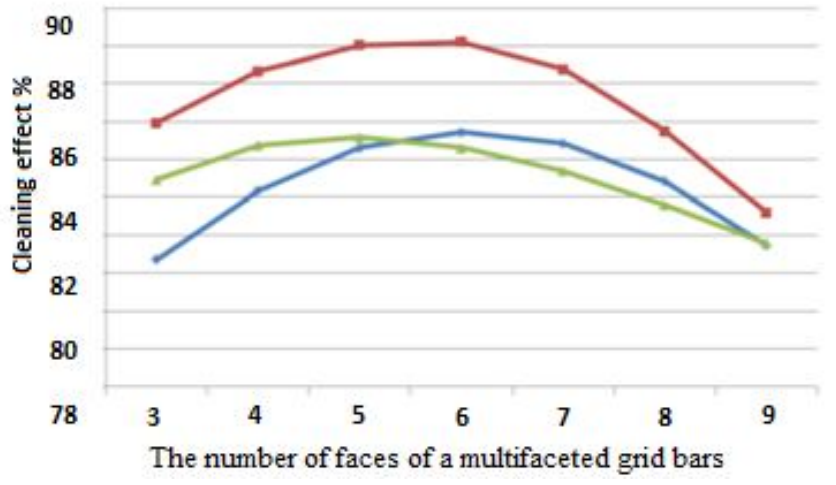

Figure 1: Graphs of changes in the cleaning effect depending on the number of faces of the grid bars

The first graph in the diagram in fig. 3.15 is determined at $\mathrm{x}_{2}$ $=14 \mathrm{~mm}, \mathrm{x}_{3}=1.5 \cdot 10^{3} \mathrm{~N} / \mathrm{m}$. Moreover, when the number of faces 3 , the cleaning effect was the lowest and amounted to $82.4 \%$, with an increase to 6 , the cleaning effect increased to $85.8 \%$, a further increase in the number of faces to 9 , the cleaning effect decreased to $82.8 \%$. The second graph is determined with a value of $x_{2}=16 \mathrm{~mm}, x_{3}=3 \times 10^{3} \mathrm{~N} / \mathrm{m}$. Moreover, when the number of faces 3 , the cleaning effect increased and reached the highest value of $87.0 \%$, with increases in faces up to 6 , the cleaning effect increased by $88.2 \%$, while increasing to 9 the cleaning effect decreased and amounted to $83.6 \%$. The third graph was obtained in experiments with high values of $\mathrm{x}_{2}=18 \mathrm{~mm}, \mathrm{x}_{3}=4.5 \times 10^{3} \mathrm{~N}$ / $\mathrm{m}$ changes in the number of faces. At the same time, when the number of faces of the grid bars was 3, the cleaning efficiency was $84.5 \%$, with increases in faces to 6 , the cleaning effect increased by $85.2 \%$. An analysis of the graphs shows that with smaller values of the number of faces, the cleaning effect was small, with a further increase in the number of faces to an average value, the cleaning effect increased. When the number of faces was 6 , the greatest cleaning effect was achieved, i.e. accounted for $88.2 \%$ [19]. In fig. 2 shows graphs of the dependences of the cleaning effect on the gap between the cylinder spiky and the grid bars.

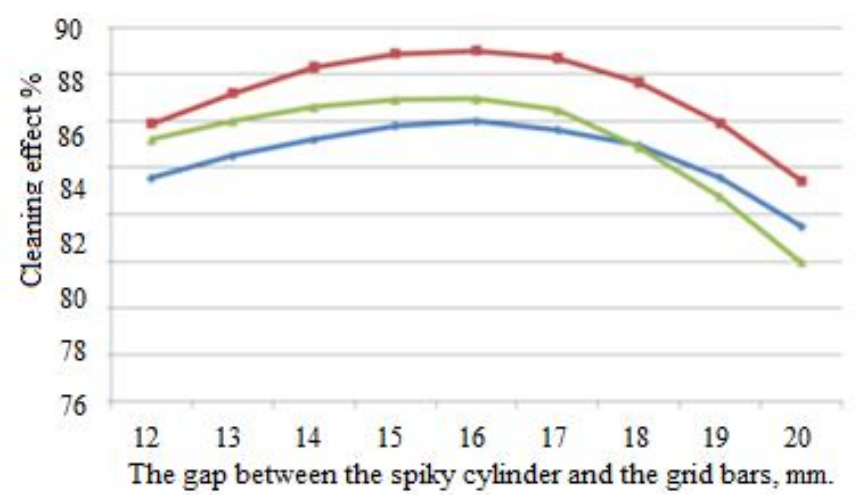

Figure 2: Graphs of changes in the cleaning effect depending on the gap between the spiky and the grid bars 
Ozod Rajabov et al., International Journal of Emerging Trends in Engineering Research, 8(9), September 2020, $6022-6029$

With an increase in the clearance by the cylinder spiky and the grid bars from $\mathrm{x}_{2}=12 \mathrm{~mm}, \mathrm{x}_{2}=20 \mathrm{~mm}$, a graph of the change in the cleaning effect is obtained. On chart 1 , at low values of $x_{1}$ and $x_{3}$, i.e. $x_{1}=4, x_{3}=1.5 \times 10^{3} \mathrm{~N} / \mathrm{m}$. An experiment was conducted with a change in the gap between the cylinder spiky and the grid bars. Moreover, when the gap between the spiky and the grid bars $\mathrm{x}_{2}=12 \mathrm{~mm}$, the cleaning effect was $83.4 \%$, when $\mathrm{x}_{2}=16 \mathrm{~mm}$, the cleaning effect was the highest, up to $86 \%$. However, with a further increase in the gap $\mathrm{x}_{2}=20 \mathrm{~mm}$, the cleaning effect decreased to $81.2 \%$. Figure 2 shows the nature of the change in the cleansing effect at average values $x_{1}, x_{3}$ i.e. $x_{1}=6, x_{3}=3 \times 10^{3} \mathrm{~N} / \mathrm{m}$. When, the gap between the spiky of the grid bars $x_{2}=12 \mathrm{~mm}$, the cleaning effect was $86.0 \%$, and with $\mathrm{x}_{2}=16 \mathrm{~mm}$ it increased to $88.9 \%$, when $\mathrm{x}_{2}=20 \mathrm{~mm}$ the cleaning effect decreased and amounted to $83.4 \%$. Figure 3 shows the result of a change in the cleansing effect at high values of $x_{1}$ and $x_{3}$, i.e. with $x_{1}=8$, $\mathrm{x}_{3}=4.5 \times 10^{3} \mathrm{~N} / \mathrm{m}$. When the gap between the spiky and the grid bars $\mathrm{x}_{2}=12 \mathrm{~mm}$, the cleaning effect was $83 \%$, and with $\mathrm{x}_{2}=16 \mathrm{~mm}$ the cleaning effect increased to $87 \%$, with an increase in $\mathrm{x}_{2}=20 \mathrm{~mm}$, a decrease in the cleaning effect was observed to $82.0 \%$ [20].

The results obtained and the constructed graphs showed that with a gap between the spiky and the grid bars of 15-16 mm, the greatest cleaning effect was achieved [21].

In fig. 3 shows graphs of the effect of the stiffness coefficient of the rubber sleeve on the supports of a multifaceted grid bars. In the graph, curve 1 is obtained at low values of $x_{1}$ and $\mathrm{x}_{2}$, curve 2 at medium values and curve 3 at high values. In this case, the influence of the stiffness coefficient of the rubber sleeve, with an increase from $\mathrm{x}_{3}=1.5 \times 10^{3} \mathrm{~N} / \mathrm{m}$ to $\mathrm{x}_{3}=4.5$ $\times 10^{3} \mathrm{~N} / \mathrm{m}$ of the multifaceted grid bars, was studied.

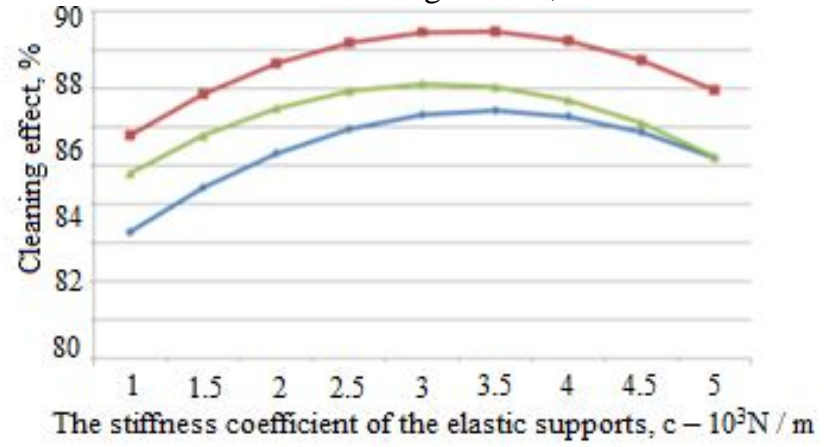

Figure 3: Graphs of changes in the cleaning effect depending on the stiffness coefficient of the rubber support of the multifaceted grid bars

An experiment was carried out at low values of $x_{1}=4, x_{3}=14$ $\mathrm{mm}$ with a change in the stiffness coefficient of the rubber sleeve. When, the rubber hardness was $\mathrm{x}_{3}=1.5 \times 10^{3} \mathrm{~N} / \mathrm{m}$, the cleaning effect was $84.9 \%$, with an increase in hardness to $\mathrm{x}_{3}=3 \times 10^{3} \mathrm{~N} / \mathrm{m}$, the cleaning effect increased to $87.2 \%$. A further increase in the stiffness coefficient to $x_{3}=4.5 \times 10^{3} \mathrm{~N}$ $/ \mathrm{m}$, the cleaning effect decreased to $85.2 \%$. Graph 2 of the diagram shows the results of the study of the cleansing effect with average values of $x_{1}$ and $x_{2}$, i.e. $x_{1}=6, x_{2}=16 \mathrm{~mm}$. At low values, $\mathrm{x}_{3}=1.5 \times 10^{3} \mathrm{~N} / \mathrm{m}$, the stiffness coefficient of the rubber support of the multifaceted grid bars, the cleaning effect was $85.8 \%$, while hardness $\mathrm{x}_{3}=3 \times 10^{3} \mathrm{~N} / \mathrm{m}$ increased to $89.2 \%$, a further increase in stiffness to $x_{3}=4.5 \times 10^{3} \mathrm{~N} / \mathrm{m}$ reduced the cleaning effect to $87.8 \%$. Figure 3 of the diagram shows the results of experiments at high values, $\mathrm{x}_{1}=8, \mathrm{x}_{2}=18$ $\mathrm{mm}$. When the stiffness coefficient of the rubber support of the grid bars was $\mathrm{x}_{3}=1.5 \times 10^{3} \mathrm{~N} / \mathrm{m}$, the cleaning effect was $83.8 \%$. With an increase in $\mathrm{x}_{3}=3 \times 10^{3} \mathrm{~N} / \mathrm{m}$, the cleaning effect increased to $88.0 \%$, a further increase in the stiffness of the rubber sleeve to $\mathrm{x}_{3}=4.5 \times 10^{3} \mathrm{~N} / \mathrm{m}$ the cleaning effect decreased to $85.2 \%$ [22].

Analysis of the graphs indicates the influence of the stiffness coefficient of the rubber sleeve on the cleaning effect. When the stiffness coefficient of the rubber sleeve was in the range $(3 \div 3.5) \times 10^{3} \mathrm{~N} / \mathrm{m}$, the greatest cleaning effect was achieved [23], [24].

\section{CONCLUSION}

Thus, based on multivariate experiments, the optimal values of an improved machine for cleaning cotton from small trash are determined. The optimal values of the parameters of the grid bars are determined based on the analysis of general graphs and the solution of regression equations. Depending on this, the recommended parameter values are: $\mathrm{n}=6, \delta=15$ $\mathrm{mm}$, the stiffness coefficient of the rubber support of the grid bars with $\mathrm{c}=3 \times 10^{3} \mathrm{~N} / \mathrm{m}$. With these optimal values, the cleaning effect of the UHK machine is $89.2 \%$.

\section{REFERENCES}

[1] R.K. Rosulov and A.A. Saphoyev. To the problems of cleaning of hard - grades raw cotton, Journal of Textile Science \& Engineering, Volume 5 Issue 2, 2015, pp. 67-72.

[2] Deshmukh D. T. and Lunge H. S. Impact of Global Warming on Rainfall, And Cotton Lint With Vulnerability Profiles of Five Districts In Vidarbha, International Journal of Scientific \& Technology Research, vol. 1, is. 11, 2012. pp. 77-85.

[3] Juraev Anvar and Rajabov Ozod. Analysis of the interaction of Fibrous Material with a Multifaceted Grid of the cleaner, International Journal of Recent Technology and Engineering, vol. 8, 1, 2019, pp. 2661-2666.

[4] M. O. Wankhade and U. V. Kale. Multiple Regression Model For Optimization of Yield of Cotton In Rain Fed Zone of Maharashtra, International Journal of Scientific \& Technology Research, vol. 8, is. 12, 2019, pp. 208-211.

[5] A. Juraev and O. Rajabov. Experimental study of the interaction of multifaceted and cylindrical spiky cylinder in cotton cleaner from small waste, International Journal of Advanced Research Science. 
Ozod Rajabov et al., International Journal of Emerging Trends in Engineering Research, 8(9), September 2020, $6022-6029$

Engineering and Technology, vol. 6, 3, 2019, pp. $8382-8387$.

[6] A.Djuraev, Sh. Kh. Madrakhimov, A.P. Mavlyanov and S. Urinova. Development and Substantiation of the Parameters of the Battery Mechanism with Elastic Elements of the Weaving Machines, International Journal of Innovative Technology and Exploring Engineering, Volume-9, Issue-3, 2020, pp. 3343-3348.

[7] A. Juraev, D.S. Tashpulatov, S.M. Elmanov, A.F. Plekhanov and R.O. Zhilisbayeva. Effective technology of natural fiber cleaner from impurities on elastic supports and justification of grate parameters, Journal, textile industry Technology, No. 6, 2018, pp. $70-75$.

[8] A. Juraev, D.S. Tashpulatov, S.M. Elmanov, A.F. Plekhanov and R.O. Zhilisbayeva. Development of resource-saving technology of natural fiber cleaner from impurities and justification of the parameters of the grate on elastic supports, Journal, Textile industry Technology, No 6, 2018, pp. 76-79.

[9] R.K. Rosulov and A.A. Saphoyev. To the problems of cleaning of hard - grades raw cotton, Journal of Textile Science \& Engineering, Volume 5 Issue 2, 2015, pp. 67-72.

[10] Kathirvel K, Vignesh P, Yuvaraj N, Vignesh kumar P and Sivaraman M. Design And Fabrication Of Cotton Wrenching Machine, International Journal of Scientific \& Technology Research, vol. 9, is. 01, 2020, pp. 3147-3150.

[11]A. Juraev, Sh.Sh. Kenjaboyev and A. Akbarov. Development of construction and calculation of frictional force in rotational kinematic pair of the fifth class with longitudinal crooves. Volume-5, Issue-9, September 2018, pp. 6778-6785.

[12] Rashidov Rahmatullo Alojonovich. Economic Efficiency of Resource-Saving Technologies In the Cotton Industry System Of Indicators, International Journal of Scientific \& Technology Research, vol. 8, is. 11, 2019, pp. 3861-3863.

[13]O. Rajabov, K. Fazliddin, and Sh. Salimov. Substantiation of Parameters of the Fibrous Material Cleaning Zone, International Journal of Engineering and Advanced Technology, vol. 9, 3, 2020, pp. 1052-1057.

[14] O. I. Rajabov, A. S. Abrorov, N. I. Mirzaqulova, G. B. Zaripov and Kh. S. Ziyodullaev. An experimental study of the location of the grid bars cells installed under spiked cylinders in a cotton cleaner from small waste, IOP Conference Series: Materials Science and Engineering, 2020, 862032049.

[15] Ozod Rajabov, Fazliddin Kurbonov, Mastura Gapparova and Shakhrillo Jumaev. The influence of the location of the cells on the allocation of weed impurities for cleaning raw cotton from fine waste, IOP Conference Series: Materials Science and Engineering, 2020, 862 032027.
[16] Akbar Abrorov, Matluba Kuvoncheva, Ozod Rajabov, Mukhsin Mukhammadov and Shakhrillo Jumaev. Method of thermal treatment of saw disk teeth of fiber- processing machines by laser quenching, IOP Conference Series: Materials Science and Engineering, 2020, 862032034.

[17]Z. Shodiyev, A. Shomurodov and O. Rajabov. The results of the experimental nature of the vibrations of the grid cotton cleaner, IOP Conference Series: Materials Science and Engineering, 2020, 883 012169 https://doi.org/10.1088/1757-899X/883/1/0121 69

[18] Rajabov Ozod Isroilovich, The influence of the mode of movement of the pieces cotton when interacting with a cotton grid, International Journal of Advanced Research in Science, Engineering and Technology. Vol. 6, Issue 3, (2019). pp. 8455-8381.

[19] Ozod Rajabov and Ziyodullo Shodiyev, Analysis of Small Fluctuations of a Multifaceted Mesh under the Influence of Technological Load from the Cleaned Cotton - Raw, International Journal of Advanced Research in Science, Engineering and Technology, Vol. 6, Issue 10, (2019), pp. 11396-11399.

[20] Bekhruz Gaybulloev, Nigina Ergasheva, Ozod Rajabov, The Structure of the Embroidery Machine and Dynamic Analysis of the Needle Mechanism, International Journal of Advanced Research in Science, Engineering and Technology, Vol. 7, Issue 1, (2020). pp. 8376-8381.

[21] Anvar Djuraev and Ozod Isroilovich Rajabov, Substantiation of the main parameters of the cylinder with multifaceted spiked of the cotton cleaner from small waste, International scientific and practical conference Innovative ideas of modern youth in science, (2019), USA. P. 149-151

[22] Mavlyanov Aybek Palvanbaevich, Rajabov Ozod Isroilovich and Yakubova Aziza Vakil qizi, Study of the influence of the parameters of the plastic grate on elastic supports with nonlinear stiffness on the oscillation frequency, International scientific and practical conference "Innovative ideas of modern youth in science", 2019, USA. P. 152-154

[23] Smirnova Zhanna.V, Vaganova O.I., Chaykina Zh. V., Golubeva O.V. Calculation of metallurgical processes during welding, International Journal of Emerging Trends in Engineering Research, Volume 8. No. 5, May 2020, pp 1529-1534

[24] A.M.Mahaboob Basha, M.Rajaiah, P.Penchalaiah, CH.Raja Kamal, B.Niranjana Rao. Machine Learning-Structural Equation Modeling Algorithm: The Moderating role of Loyalty on Customer Retention towards Online Shopping, International Journal of Emerging Trends in Engineering Research, Volume 8. No. 5, May 2020, pp 1578-1585 